\title{
¿UNA ARDILLA QUE VUELA?
}

\author{
Bárbara Vargas-Miranda1* y Claudia Ballesteros-Barrera² \\ 1Departamento de Ciencias de la Salud. División de Ciencias Biológicas y de la Salud, \\ Universidad Autónoma Metropolitana-Iztapalapa, Ciudad de México, Ciudad de \\ México,México. bvm@xanum.uam.mx \\ 2 Departamento de Biología.División de Ciencias Biológicas y de la Salud, Universidad \\ Autónoma Metropolitana-Iztapalapa, Ciudad de México, Ciudad de México, México. \\ bbc0711@gmail.com \\ *Autor de correspondencia
}

En una noche oscura en un bosque, escuchamos ruidos en los árboles, algunas ramas se han movido. De pronto vemos una pequeña silueta surcar el cielo: "no es un ave, no es un avión, no es Superman, es ¡Glaucomys volans, la ardilla voladora!".

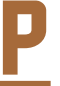

or allí dicen que en el nombre se lleva la fama, pero esto no es necesariamente cierto, por ejemplo "volans" en latín significa volar, sin embargo, la ardilla voladora no tiene alas como las aves o los murciélagos, pues en realidad no vuelan, sino planean, pero su nombre se debe a que pueden ejecutan un salto a una distancia de ocho a 11 metros de una sola vez, incluso hay reportes que indican que pueden descender por una pendiente hasta 30 o 90 metros. Pero este desplazamiento a grandes distancias se debe a su capacidad de girar de 90 y 180 grados para evitar obstáculos.

La sorpresa de ver a estas ardillas planear sin titubear en ningún momento, nos permite admirar las adaptaciones de estos hermosos animales. Sin miedo, Glaucomys volans planea de un árbol a otro, solo necesitan que exista una pendiente muy pronunciada para hacer esta destreza. Al visitar las laderas más húmedas de los bosques templados densos, en los que los encinos dominan y donde predominan los bosques de pino o pino-encino en México, distinguimos árboles secos con orificios o cavidades hechas por los pájaros carpinteros. Esos orificios, los utiliza la ardilla voladora para refugiarse y reproducirse. Los orificios se encuentran regularmente en lo más alto del tocón, aproximadamente de 20 hasta 40 metros de alto. Al golpear los tocones con una piedra grande o un palo, se asoman las curiosas ardillas para ver qué es lo que está pasando. Si se continúa golpeando el tocón, se sienten amenazadas y estás saltan o planean a otros árboles cuesta abajo, en una pendiente de 45 grados. Si la ardilla llega a caer al suelo, muestra un comportamiento muy parecido al de los demás sciúridos (Sciuridae es la Familia a la que pertenecen las ardillas), pues al subir a un árbol para alejarse, le da una vuelta de 180 grados al troco para después comenzar el ascenso, si uno sigue la trayectoria del animal sin perderlo de vista, este sigue dando vueltas al troco mientras asciende, seguramente con la intención de perder la amenaza del depredador.

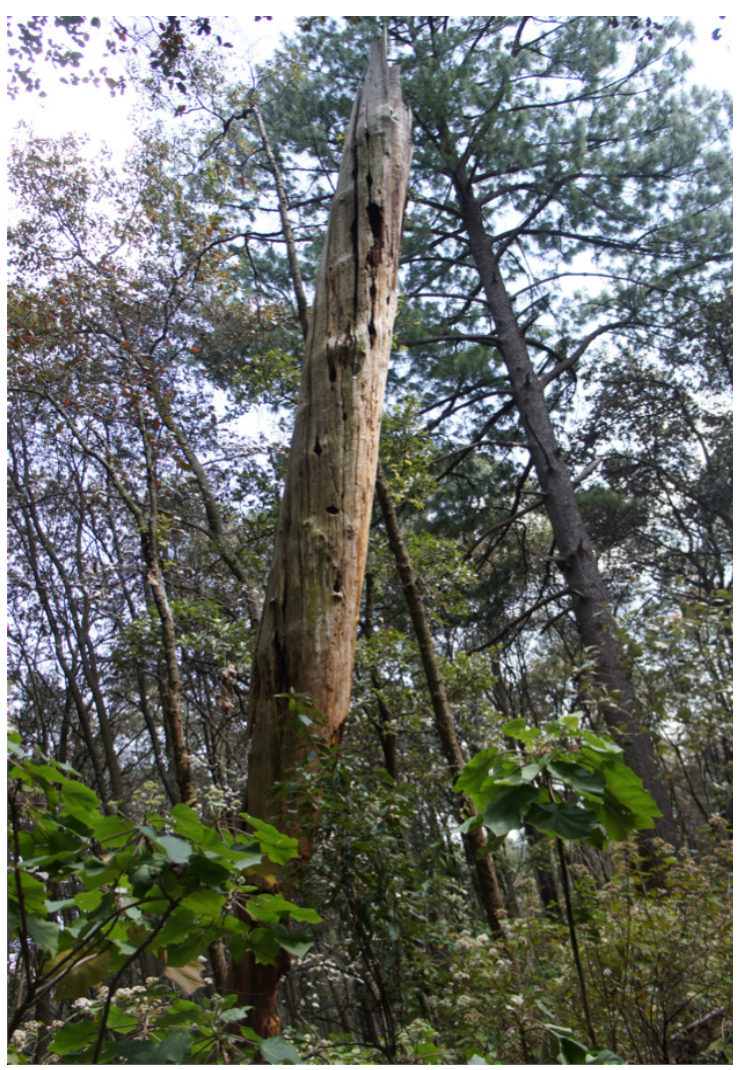

Tocón en Chapa de Mota, Estado de México, México. Fotografía: E. Vieyra-Vargas

Cuando planean, su estrategia es extender o desplegar sus patagios, que son una membrana de piel que van desde los huesos de la muñeca hasta el tobillo de la pata trasera. En las patas delanteras están sostenidas por un espolón cartilaginoso que parte de las articulaciones de las manos. Los patagios son dos capas de piel, en donde hay unos músculos que permiten a estas ardillas cambiar la cubertura de la superficie planeadora para modificar rasgos aerodinámicos. Además, para guiar su planeo, usa su cola peluda y plana como timón, lo que le permite llegar a otro árbol. Para esto coloca su cuerpo en 
posición vertical, lo que le permite llegar al otro árbol sin caer al suelo. En la superficie dorsal de las falanges ungueales (unos huesitos que se encuentran en los extremos de los dedos de las patas), más allá de las puntas de las garras, se extienden vibrisas o pelos rígidos más o menos largos que actúan como receptores táctiles.

Sus ojos, son grandes y oscuros, lo que le permite ver en la oscuridad, debido a que son las únicas ardillas de hábitos nocturnos del país. En el día no tienen actividades, pues son presa fácil de gavilanes, águilas, halcones y búhos. Pero en la noche son muy silenciosas y se puedan desplazar por los árboles sin ser vistas. Sus nidos o madrigueras los hacen en los orificios de los tocones y usan como cama el musgo, líquenes, plumas, ramas y hojas de los árboles. En cada madriguera pueden ser habitada de dos a siete ardillas. También en sus madrigueras se han observado restos de bellotas o estróbilos de encinos y pinos, con pequeños orificios que ellas hacen con sus fuertes incisivos para obtener el endospermo, ricos en nutrientes, o quitan las escamas de los estróbilos femeninos de los pinos, para extraer las semillas maduras. Estas ardillas son omnívoras, pero se encuentran entre las ardillas más carnívoras, pues se han encontrado restos de élitros de escarabajos y otros invertebrados, además de aves, huevos, polluelos y carroña de otros mamíferos. En otoño e invierno, casi no son visibles en los tocones, pues están inactivas por el clima frío. En verano y primavera, aprovechan en estas estaciones para almacenas alimento en los huecos de sus nidos, el cual consumen en invierno cuando el alimento es menos disponible.

Hay muchas especies de ardillas, pero sin duda la ardilla voladora es particularmente extraordinaria, sin embargo, sus poblaciones están siendo fuertemente amenazadas debido a su fragmentada distribución y a la destrucción de los bosques que constituyen su hábitat. Es una especie considerada como "amenazada" en la Norma Oficial Mexicana NOM-059-SEMARNAT-2010. Por lo cual se requieren más estudios sobre su biología y más esfuerzos para asegurar su conservación.

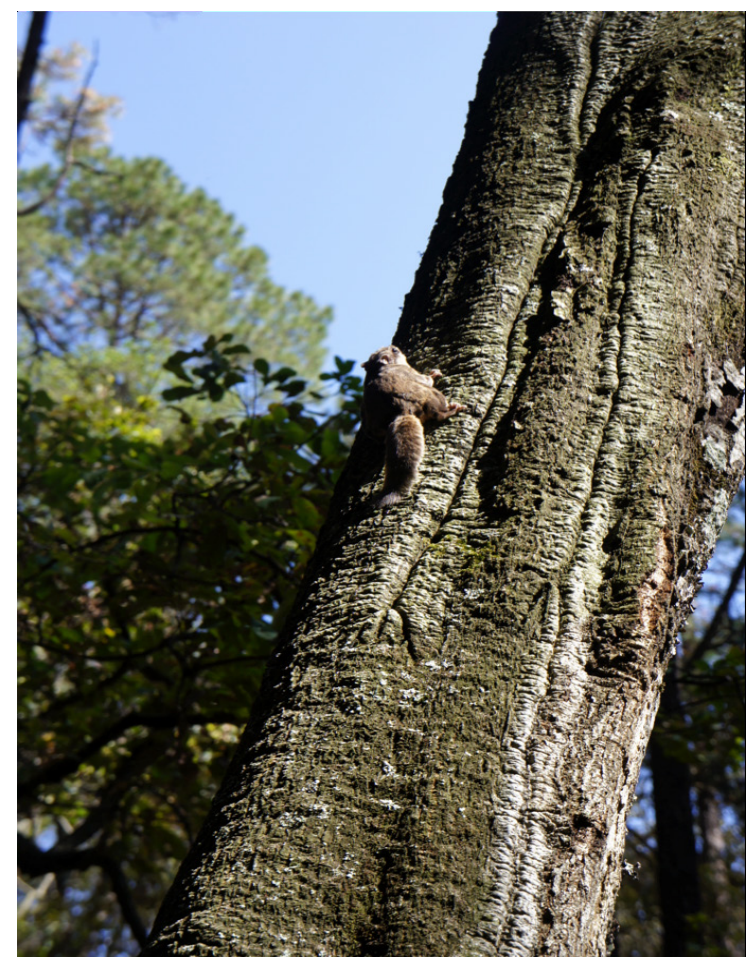

Ardilla voladora (Glaucomys volans) en Chapa de Mota, Estado de México, México. Fotografía: E. Vieyra-Vargas
Ahora sabemos que la ardilla voladora, se puede ver en una noche oscura en un bosque y si escuchas ruidos en los árboles y ves que algunas ramas se han movido, puede ser que te está observando un mamífero volador.

\section{AGRADECIMIENTOS}

Extendemos un cordial agradecimiento al Biól. S. Gaona Ramírez de la UAM Iztapalapa, al proporcionarnos parte de la información. Al Biól. L. D. García González por su invaluable colaboración en las salidas al campo para monitorias las poblaciones de Glaucomys volans en Chapa de Mota, en el Estado de México. Agradecemos a la Universidad Autónoma Metropolitana Unidad Iztapalapa que nos apoyó con permisos y transporte para el estudio de esta ardilla.

\section{LITERATURA CONSULTADA}

Ceballos, G. y C. Galindo. 1983.Glaucomys volans goldmani (Rodentia: Sciuridae) in Central México. The Southwestern Naturalist 28:375376

Ceballos, G. y P. Manzano. 2005.Glaucomys volans. Pp. 531-533. en Los mamíferos silvestres de México. (Ceballos G. y G. Oliva, eds.) CONABIO y Fondo de Cultura Económica. Distrito Federal, México.

Ceballos, G. y A. Miranda. 1985. Notes on the biology of Mexican flying squierrels (Glaucomys volans) (Rodentia: Sciuridae). The Southwestern Naturalist30:449-450.

Ceballos G. et al. 2010. Geographic Distribution, Genetic Diversity, and Conservation Status of the Southern Flying Squirrel (G/aucomys volans) in México. Occasional Papers, Museum of Texas Tech University 299:1-14.

Ceballos, G. (Ed.). 2015. Los mamíferos silvestres de México. Comisión Nacional para el Conocimiento y Uso de la Biodiversidad y Fondo de Cultura Económica, Distrito Federal, México.

Diersing, V. E. 1980. Systematics of flying squierrels, Glaucomys volans (Linnaeus), from Mexico, Guatemala and Honduras. The Southwestern Naturalist 25:152-172.

Dolan, P. G., y D. C. Carter. 1977. Glaucomys volans. Mammalian Species 78:1-6.

Hooper, E. T. 1952. Records of the flying squirrel (Glaucomys volans) in Mexico. Journal of Mammalogy 33:109-110.

Secretaría del Medio Ambiente y Recursos Naturales, 2010. Norma Oficial Mexicana Nom-059 SEMARNAT-2010, Protección ambientalEspecies nativas de México de flora y fauna silvestres-Categorías de riesgo y especificaciones para su inclusión, exclusión o cambioLista de especies en riesgo. Diario Oficial de la Federación. México. 30 de diciembre de 2010.

Thornback, J., y M. Jenkins. 1982. The IUCN mammal red data book. Part I. IUCN. Gland, Switzerland.
Sometido: 02/dic/2021

Revisado: 03/dic/2021

Aceptado: 04/dic/2021

Publicado: 08/dic/2021.

Editor asociado: Dr. Juan Pablo Ramírez-Silva. 